\title{
VITAMIN D LEVELS AND ITS ASSOCIATION WITH OXIDATIVE STRESS MARKERS AND INFLAMMATORY PROCESS IN PATIENTS WITH CYSTIC FIBROSIS
}

\author{
Dayanna Queiroz ${ }^{1}$, Alexandre Silva ${ }^{2}$, Celso C S Junior Junior ${ }^{2}$, Darlene Persuh ${ }^{2}$, Alcides \\ Diniz $^{3}$, Rafaela Lima ${ }^{2}$, Maria Paula Paiva ${ }^{2}$, Constantino Cartaxo ${ }^{2}$, Patricia Bezerra ${ }^{3}$, \\ Maria da Conceição Goncalves ${ }^{1}$, and Mateus Ribeiro ${ }^{2}$ \\ ${ }^{1}$ Universidade Federal da Paraíba \\ ${ }^{2}$ Universidade Federal da Paraiba \\ ${ }^{3}$ Universidade Federal de Pernambuco
}

October 20, 2021

\begin{abstract}
Introduction: Cystic Fibrosis is a disease that causes inflammation, oxidative stress and metabolic changes that lead to nutrient deficiency, such as vitamin D. On the other hand, it is suggested that vitamin D has anti-inflammatory and antioxidant action. Objective: To evaluate the prevalence of hypovitaminosis D and the association between serum 25 hydroxyvitamin D levels with markers of oxidative stress and inflammation in patients with cystic fibrosis. Method: Cross-sectional study carried out with 48 patients with Cystic Fibrosis in children, adolescents and adults in the Northeast region/Brazil. Blood collection was performed for analysis of 25-hydroxyvitamin D, calcium, parathyroid hormone, inflammatory process (C-reactive protein -PCR and alpha-1-acid glycoprotein-A1-A1GPA) and oxidative stress (malondialdehyde-MDA and total antioxidant capacity-CAOT. Statistical analysis was performed using the "Statistical Pacage for the Social Sciences", adopting a significance level of $\mathrm{p}<0.05$. Results: Insufficiency/deficiency of D was found in $64.6 \%$ of patients. After multiple linear regression analysis, MDA showed an inverse association with blood values of 25 -Hydroxyvitamin D $(\mathrm{p}<0.05)$ Results: Insufficiency/deficiency of D was found in $64.6 \%$ of patients. After multiple linear regression analysis, MDA showed an inverse association with blood values of $25-$ Hydroxyvitamin D $(\mathrm{p}<0.05)$ conditioned on the presence of inflammatory process markers. When only oxidative stress is evaluated, this association disappears. Conclusion: In conclusion, there was a high prevalence of hypovitaminosis D, with 25 (OHD) levels associated with greater oxidative stress when combined with inflammatory markers. Improved vitamin D levels may be an alternative to reduce the damage caused by excess oxidative stress and inflammation in CF patients.
\end{abstract}

\section{Hosted file}

arquivo1semtables.doc available at https://authorea.com/users/442117/articles/542456-vitamind-levels-and-its-association-with-oxidative-stress-markers-and-inflammatory-process-inpatients-with-cystic-fibrosis

\section{Hosted file}

tabelas.doc available at https://authorea.com/users/442117/articles/542456-vitamin-d-levelsand-its-association-with-oxidative-stress-markers-and-inflammatory-process-in-patientswith-cystic-fibrosis 